\title{
Metapragmatic stereotypes about geographical diversity in Greece
}

\section{Evidence from elementary school pupils' responses to mass culture texts*}

\author{
Dimitris Papazachariou \\ University of Patras \\ papaz@upatras.gr \\ Anna Fterniati \\ University of Patras \\ afterniati@upatras.gr \\ Argiris Archakis \\ University of Patras \\ archakis@upatras.gr \\ Vasia Tsami \\ University of Patras \\ tsamibasil@gmail.com
}

\begin{abstract}
Over the past decades, contemporary sociolinguistics has challenged the existence of fixed and rigid linguistic boundaries, thus focusing on how the speakers themselves define language varieties and how specific linguistic choices end up being perceived as
\end{abstract}

* The present study was conducted in the context of the Operational Program "Education and Lifelong Learning" and has been co-funded by the Eu (European Social Fund) and national resources. In particular, it was part of the Greek research program Thalis (2011-2015), entitled: "Linguistic variation and language ideologies in mass cultural texts: Design, development and assessment of learning material for critical language awareness" (Ministry of Education and Religious Affairs, Funding ID: MIS 375599). The authors would like to thank Dr. Villy Tsakona for her helpful suggestions.

(C) DIMITRIS PAPAZACHARIOU, ANNA FTERNIATI, ARGIRIS ARCHAKIS AND VASIA TSAMI, 2018 | DOI: 10.1163/15699846-01801002

This is an open access article distributed under the terms of the prevailing CC-BY-NC license 
language varieties. In this light, the present paper explores the influence of metapragmatic stereotypes on elementary school pupils' attitudes towards geographical varieties. Specifically, we investigate children's beliefs as to the acceptability of geographical varieties and their perception of the overt and covert prestige of geographical varieties and dialectal speakers. Furthermore, we explore the relationship between the children's specific beliefs and factors such as gender, the social stratification of the school location and the pupils' performance in language subjects. The data of the study was collected via questionnaires with closed questions. The research findings indicate that the children of our sample associate geographical varieties with rural settings and informal communicative contexts. Moreover, children recognize a lack of overt prestige in geographical variation; at the same time, they evaluate positively the social attractiveness and the personal reliability of the geographical varieties and their speakers. Our research showed that pupils' beliefs are in line with the dominant metapragmatic stereotypes which promote language homogeneity.

\section{Keywords}

elementary school pupils - language attitudes - metapragmatic stereotypes - geographical varieties - mass culture texts

Contemporary sociolinguistics has recently displayed "a shift away from structure, system, and regularity toward approaches that acknowledge fluidity and creativity in linguistic practices" (Busch 2012: 506). According to Eckert (2012: $98)$, third wave sociolinguistics "locates ideology in language itself, in the construction of meaning, with potentially important consequences for linguistic theory more generally". In other words, the emphasis of contemporary sociolinguistics has started to move from linguistic rules and formulas that constitute language systems towards the ideological schemes that can be used by the speakers to evaluate the "correctness" of a person's speech and to set the limits of a variety (Johnstone 2009: 16o). From Agha's (2007: 148) point of view, these ideological schemes could be seen as "the metapragmatic stereotypes of speech, i.e., culture-internal models of utterance indexicality associated with speech variants" (see also Agha 1998, 2004). Metapragmatic stereotypes play a decisive role in shaping speakers' beliefs and language attitudes (see e.g. Agha 1998, 2004, 2007). Throughout their lives, speakers acquire metapragmatic stereotypes, which affect their sociolinguistic behavior. 
The aim of the present study is to explore how elementary school pupils perceive geographical varieties and to identify the metapragmatic stereotypes underlying their perception. Specifically, we investigate children's beliefs concerning the acceptability of geographical varieties, that is, the communicative circumstances in which they consider the use of geographical varieties acceptable. Further attitudinal tests allow us to look into the children's beliefs concerning the overt and covert prestige of geographical varieties and dialect speakers (Trudgill 1974, 1975). Furthermore, we investigate the possible interrelation between the children's specific beliefs and factors such as gender, the social stratification of the school population, and the pupils' performance in language and literature.

The paper begins by defining the term metapragmatic stereotypes and determining their role in shaping language attitudes (Section 2). This is followed by a brief review of sociolinguistic studies conducted both in Greece and outside Greece, on language attitudes to geographical varieties (Section 3). The paper then describes the methodology implemented for designing and conducting the study (Section 4). Section 5 presents and discusses the research findings, while the last Section (6) presents some concluding remarks on the results of the analysis.

\section{2 Language attitudes and the role of metapragmatic stereotypes}

Over a period of several decades, traditional linguistics laid particular emphasis on strict linguistic boundaries and the connection of languages and language varieties to geographical and/or social contexts. In other words, a language variety used by a speaker was considered to reflect the place of origin and the social group to which this person belonged (Hudson 1996).

Recent decades have witnessed a tendency to challenge the positions of this traditional approach (Blommaert and Rampton 2011:3). There is now a substantial body of work that denaturalizes the idea of proper, discrete, bounded and autonomous languages and language varieties. As Johnstone (2011b: 3) aptly points out in reference to dialects, "[d]ialect boundaries are not inscribed on the landscape, so the world does not present itself to linguists with dialects waiting to be discovered". Language and language varieties are not defined as fixed and homogenous entities linked with a specific geographical area or social group (Blommaert and Rampton 2011; Otsuji and Pennycook 2010; Rampton 1995). A more dynamic perspective has been put forward whereby language, language varieties, and linguistic elements are approached as resources available to speakers, who can draw upon them according to the social identities 
they potentially wish to project (Blommaert and Rampton 2011: 10; Busch 2012, 506). Thus, different linguistic choices can be seen as "constructions which can be more or less temporary and situation-specific" (Hinskens and Guy 2016: 3; see also Guy 2013). Consequently, it is not always easy to locate a language variety or to pin down the socio-cultural background of a speaker and/or the social group to which (s)he belongs, when we hear him/her speaking (Blommaert and Rampton 2011: 4; see also Johnstone 2009, 2011a, 2011b; Johnstone, Andrus, and Danielson 2006).

In this context, emphasis is placed on critical approaches to what the speakers themselves define as a language or language variety, and to how specific linguistic choices come to be seen as language varieties. The concept of language is viewed as an ideological construct, shaped under the influence of social, political, and historical factors (Blommaert 2006: 242; Piller 2001: 261; see also Makoni and Pennycook 2007). Contemporary sociolinguistic research therefore focuses not on the geographical and/or social boundaries of a variety, but on the speakers' beliefs about the function and geographical and/or social context of a variety. As a result, particular emphasis is placed upon the study of speakers' language attitudes (see, among others Baker 1992; $\Gamma \rho i \beta \alpha$ and $\Sigma \tau \dot{\alpha} \mu 0 v$

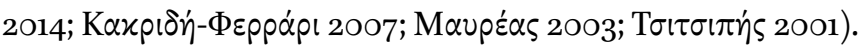

Language attitudes are shaped by views, prejudices, and stereotypes about the nature and characteristics of various languages. To use the terms of anthropologists such as Silverstein (1992, 1993, 2003) and Agha (1998, 2004, 2007), language attitudes stem from language ideologies or metapragmatic stereotypes shaped by speakers regarding various linguistic phenomena. Agha (2007: 148) suggests that the term metapragmatic stereotypes refers to speakers' internalized models of language use which enable them to make evaluative judgments about their own language behavior or that of others (see also Agha 1998, 2004; cf. Archakis et al. 2015). These stereotypes arise from language use and assessment, are socially circulated, and affect interactions between speakers of a language community. Based on metapragmatic stereotypes, individuals express attitudes on how specific linguistic choices function in social interaction. Speakers either express their views on various language elements directly, through describing them as 'right', 'wrong', 'appropriate', 'inappropriate', 'common', 'unusual' and so on, or express their evaluative judgments indirectly, through associating specific language elements with different social characteristics (e.g. woman, upper-class person), communicative situations (formality, politeness) and/or social practices (religious, literary, or scientific activity). So, as Agha (2007: 145) points out, "language users often employ labels like polite language, informal speech, upper-class speech, women's speech, literary usage, scientific term, religious language, slang, and others, to describe differ- 
ences among speech forms". Essentially, speakers' views prescribe how language choices are to be grouped and assessed, classifying them into different language varieties. In other words, speakers' metapragmatic stereotypes play a decisive role in shaping the boundaries of a language variety (Agha 2007:150$151,155)$.

Speakers shape their linguistic beliefs under the strong influence of language ideologies circulating in their community. In Greece, as in most western nationstates, linguistic homogenization and the marginalization of language varieties have always been dominant ideological constructs (Mooxovd́s 2005). Linguistic homogeneity and monolingualism are based on the idea that languages and language varieties are strictly bounded systems, used in specific, also bounded, social formations (Blommaert and Rampton 2011; Busch 2012; Heller 2007; Jørgensen and Juffermans 2011). Specific institutions of power, like the media and education, play a decisive role in achieving linguistic homogeneity. The discourse of the media often dictates the expected linguistic behavior through the alignment of television characters with linguistic homogeneity and the respective metapragmatic stereotypes (Moody 2013; Stuart-Smith 2006; Van den Bulck 2001). In fact, in the Greek media, television characters who do not speak the standard variety, thus not following the dominant language ideology,

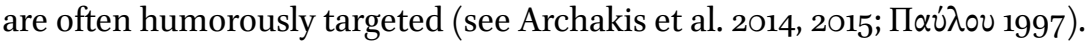

In light of the above, the present paper attempts to identify the stereotypes reflected in elementary school pupils' attitudes toward geographical varieties. More specifically, we look into how pupils shape their language attitudes, assess a geographical variety, and delimit the acceptability of its use (see also ApX $\alpha$ -

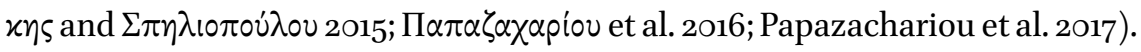
Since metapragmatic stereotypes differ even within the same speech community, we will attempt to determine whether these stereotypes vary according to the speakers' social characteristics. The next section presents the findings of research conducted both in Greece and worldwide, on the language attitudes of speakers toward various geographical varieties.

3

\section{Language attitudes towards geographical varieties: research findings}

International research on language attitudes towards geographical varieties

Early sociolinguistic research already placed particular emphasis on studying the attitudes of speakers towards the geographical variety they used or towards the geographical varieties of other communities. These studies showed that 
speakers associate the use of geographical varieties with rural environments (see, among others Dailey-O'Cain 1999; Diercks 2002; Grootaers 1999; Inoue 1999; Rensink 1999). Speakers also associate standard linguistic types with a more formal and sophisticated style, while dialect elements are considered more suitable for informal communicative circumstances (Preston 1999, 2003). Moreover, speakers assess as more proper the varieties they consider close to the standard variety, while they view nonstandard varieties as more pleasant, friendly, and familiar (Preston 1999, 2003).

The language attitudes of adults are similar to attitudes developed by children in preschool and early school ages, displaying more positive attitudes towards standard varieties, attributing greater status to them and characterizing them as 'better' (Rosenthal 1974; van Bezooijen 2002). Children who speak a nonstandard variety initially display a preference or neutral attitude towards the variety they use; however, as they grow up, they tend to prefer dominant language ideologies, favoring standard varieties (Cremona and Bates 1977; Day 1980). The development of children's language attitudes often relates to their social background, as relevant research has shown that children of a higher socioeconomic background prefer the standard variety, while children of a lower socioeconomic background prefer geographical varieties to a greater extent (Rosenthal 1974). Moreover, children seem to associate standard language speakers with higher social classes and dialect speakers with lower social classes (Rosenthal 1974).

To sum up, the speakers' dominant belief is that geographical varieties are suitable for use in rural and informal environments, while standard linguistic types are associated with formal communicative circumstances. Furthermore, factors such as the speakers' age and social background seem to affect their language attitudes.

\subsection{Greek research on language attitudes}

In Greece and Cyprus, numerous studies have addressed language attitudes towards geographical varieties. The findings of these studies have a lot in common with language attitudes of speakers observed worldwide. More specifically, in Greece, speakers predominantly associate geographical varieties with a rural and provincial environment, and the variety used in urban areas with Standard Modern Greek (SMG) (Koupóns 1997, 2001, 2002, 2007; Pappas 2006;

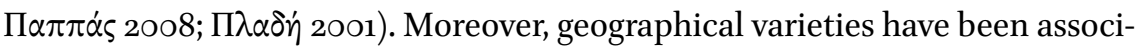
ated with informal communicative frameworks and are considered suitable for use in conversations with friends, family members, or acquaintances regard-

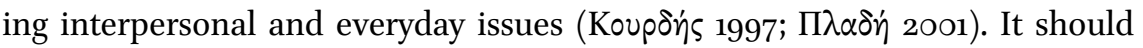
be noted that the use of geographical varieties in these circumstances is often 
assessed positively, since it is associated with the strengthening of social ties, solidarity, and with a feeling of belonging to a social group (Koupon's 2001, 2007; П П $\alpha \delta \dot{\eta}$ 2001). Then again, SMG is connected to institutionalized and formal communicative circumstances, such as education and the media (Koupon's 2001, 2007; П $\lambda \alpha \delta \dot{\eta}$ 2001). Greek speakers seem to display a negative attitude towards using geographical varieties in formal communicative circumstances, either characterizing it as 'incorrect' or simply by showing a preference for the

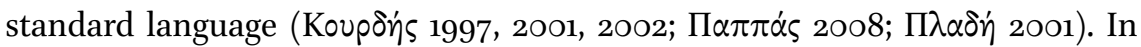
fact, the use of geographical varieties in formal communicative circumstances may entail a disadvantage for the career and social advancement of the dialect speaker, as it is interpreted as lack of education (Koupon's 2001, 2007; Pappas

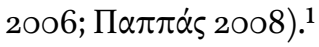

In Cyprus, speakers display similar language attitudes, as the Cypriot dialect is associated with rural and informal environments (Papapavlou 1998, 2001;

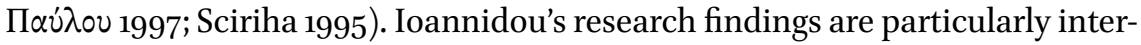
esting (Ioannidou 2009; I $\omega$ avvíov 2012); she found that the presence of the dialect in the educational domain in Cyprus was very strong, but its use related mostly to 'informal' communicative circumstances in schools, regarding the organization of the classroom and informal conversations and comments, rather than to 'the teaching process'. In the communicative circumstances of the main teaching, the language used was the standard, as it was directly connected to formality. Educators seem to be 'tolerant' towards the use of the Cypriot-Greek varieties, with 'tolerance' essentially amounting to symbolic

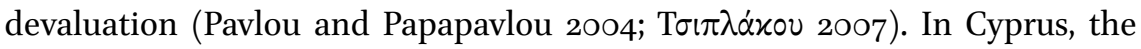
state encourages education in SMG, because it provides a powerful means of connecting Greek Cypriots to Greece, establishing a framework of linguistic homogenization. This language policy has been decisive in shaping the language attitudes of pupils; studies where the sample consisted of Cypriot-Greek

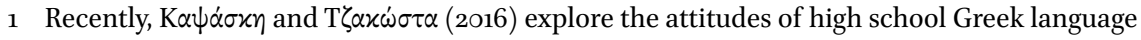
teachers who serve in Greek public secondary education, regarding the use of dialectal variants. The major finding of this research was that, although the teachers acknowledge the importance of dialectal variants and the equality of the latter to the standard language, they are skeptical regarding the possibility of dialects being incorporated in language teaching. This claim is reported regardless of whether teachers are native speakers of dialects or not.

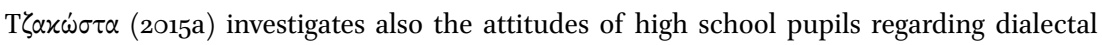
learning, use, and teaching. This study indicates that pupils make similar claims to language teachers; however, pupils' behavior is attributed to the fact that they are not allowed to use their dialect in the context of school since language varieties are considered inferior com-

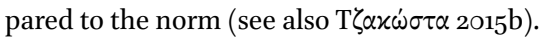


preschool (Kounnapi 2006) and elementary school pupils (Pavlou 1999) reveal the participants' negative attitude towards the Cypriot-Greek varieties. Children also associate the Cypriot dialect with lower socioeconomic background and the use of SMG with people of higher socioeconomic status (Kounnapi 2006; Pavlou 1999).

To sum up, both in Greece and in Cyprus, the speakers' dominant belief is that geographical varieties are mostly used in rural and informal communicative frameworks, while the use of the standard language is associated with formal communicative circumstances. Speakers attribute both negative and positive evaluations to the use of geographical varieties. Negative evaluations dominate when geographical varieties are used in formal communicative situations, while their use in informal contexts is often evaluated positively, as speakers interpret it as an indication of proximity and solidarity to other speakers. A negative attitude towards geographical varieties is dominant in the beliefs of children, who actually associate the use of dialects with people of lower socioeconomic status.

\section{4} Methodology

\subsection{Research questions}

The present study focuses on the dominant metapragmatic stereotypes of elementary school pupils with regard to geographical diversity. Taking into account the findings of previous research, we investigate to which extent children associate the use of geographical varieties with rural environments and informal communicative frameworks. We also explore the children's beliefs about the overt and covert prestige of dialect speakers, and whether these beliefs are affected by factors such as gender, the social stratification of population in the area of the school, and the pupils' performance in language subjects. This section outlines the methodology employed for the purposes of the study.

\subsection{Population sample}

The target group of our research consists of pupils of the last two grades of elementary school (i.e. 11 and 12 years old). In order to define the sample of our research, we used the stratified random sampling method, which involves the division of a population into subgroups, known as strata. In stratified random sampling, the strata are formed according to the members' shared characteristics or attributes. The main advantage with this method is the way it captures key population characteristics in the sample. In this study, stratified random sampling was implemented for the selection of the sample, ensuring 
that the sample represented the pupils' social stratification, depending on the area where the school is located (see Robson 2007: 310-311).

The study was conducted in May 2013 in four state elementary schools in the wider region of Achaia, a province of Southern Greece. The geographical location of our sample ensures no further attachments-actual or psychologicalof the pupils with the stimulus, since the stimulus has northern characteristics, as we will analytically present below. A total of 96 fifth- and sixth-graders were selected (11-12 years old). Depending on the social status of the area in which they are located, the four schools were classified as low (2 schools, 29 students), middle (1 school, 20 students) and high (1 school, 25 pupils). This classification was statistically confirmed (Anova Test, Sig. $=0.000$ ) by the average level of parents' education, recorded using a ten-point scale. ${ }^{2}$ Specifically, the high social status school is located very close to the University of Patras, and the majority of the pupils' parents belong to the teaching and administrative staff of the University. The middle class school is located in an area populated by self-employed workers, professionals and office employees. The two schools classified as low social status are located in mountain villages of Achaia, populated mostly by farmers and manual workers.

Apart from the social status factor for the school location, the other independent variables that characterized pupils were gender (male: $55.21 \%$, female: $44.79 \%$ ), the pupils' performance in language subjects (high: $56.25 \%$, average: $26.04 \%$, low: $17.71 \%$ ), and ethnic origin. ${ }^{3}$

\subsection{Method of data collection: questionnaire}

Data was collected through anonymous questionnaires. The pupils were asked to watch a commercial by Vodafone, which functioned as the stimulus for the pupils' questionnaire (see Section 4.4). ${ }^{4}$ Two questionnaires were designed,

2 The parents' education level was classified using a ten-point scale, where $1=$ Received no education or attended part of elementary school, $2=$ Completed elementary school, $3=$ Started but did not complete junior high school, $4=$ Completed junior high school, $5=$ Started but did not complete senior high school, $6=$ Completed senior high school, $7=$ Started but did not complete tertiary education, $8=$ Graduated from a technological institute, 9 = Graduated from university, 10 = Holds a master's degree or doctorate.

3 Regarding the variable of ethnic origin, $13.56 \%$ of the total sample consisted of pupils from Albania, Bulgaria, Romania, and Ukraine, as well as one Roma pupil. However, this specific variable was not analyzed, since the representation of above ethnic groups was too small to allow us to reach valid conclusions for the language attitudes of non-Greek pupils.

4 The present paper focuses on the findings arising from this specific commercial only. For this reason, there is no detailed description of the other two television excerpts that were used to explore the pupils' language attitudes. 
one for the pupils and one for their parents. The pupils' questionnaire included closed questions, which are analyzed in the present paper (see Appendix). The parents' questionnaire consisted of a single page, aiming at identifying the educational level of the family, through closed questions (see Section 4.2). ${ }^{5}$ Specifically, the questions prompted the children to choose in which geographical area(s) (urban, semi-urban, or rural) they would expect to hear a geographical variety similar to the one used by the $\mathrm{TV}$ ad characters. The pupils were also asked to select from among a wide range of communicative frameworks, in which circumstances they would expect to hear a geographical variety similar to the one used by the TV commercial characters. Moreover, the pupils were asked to what extent they would expect to hear a teacher, doctor, or journalist use the geographical variety of the television characters in the communicative environment of the workplace. The pupils' answers to questions of this category were classified on a four-point scale ( $1=$ Not at all likely, $2=$ A little likely, 3 $=$ Quite likely, 4 = Very likely). The three sets of questions described above aimed to find the geographical context and circumstances (communicative and professional) in which pupils consider the use of geographical varieties acceptable.

Another set of seventeen questions was included in the pupils' questionnaire, asking our informants to evaluate directly the geographical variety that was used by the TV commercial characters, with characteristics referring to competence, prestige, reliability, integrity, and attractiveness (like weird, funny, incorrect, beautiful, stupid, unappealing, outdated, cheerful, useless, indifferent, incongruous, friendly, important, intelligent, rustic and insignificant). These questions were aimed at eliciting the children's beliefs as to the overt and covert prestige of geographical varieties and dialectal speakers. ${ }^{6}$ This part of our research was inspired by numerous findings of attitudinal tests which have shown that the evaluation of particular language varieties actually reveals the informants' attitudes towards those varieties (see Apa 1984; Giles and Powesland 1975; Lambert et al. 196o; Preston 1989). The pupils' answers to questions of this category were classified on a four-point scale $(1=$

5 In order to determine the parents' education level, we used the questionnaire designed for the research conducted by $\Phi \tau \varepsilon \rho v i \alpha ́ \tau \eta ~(2001)$.

6 Numerous attitudinal tests have shown that informants' assessments on language varieties were triggered by the social values of the speakers and their communities, which reflected on the language varieties, and not by the linguistic elements themselves (see Apa Fasold 1984; Giles and Powesland 1975; Lambert, et al. 196o; Preston 1989). It is not accidental that the vast majority of the characteristics that we used in our attitudinal test can easily be attributed to the language variety, as well as to its speakers. 
Not at all, $2=$ A little, $3=$ A lot, $4=$ Definitely). The data collection lasted for a month approximately. After a pilot implementation, the questionnaires were administered to the participating schools and completed by the pupils of the sample in the presence of a researcher and their teacher. The question regarding the performance of each pupil in language subjects was completed by the teachers.

\subsection{Stimulus}

Our aim was to elicit pupils' attitudes towards the use of geographical varieties, in order to identify the metapragmatic stereotypes shaping those attitudes.

As mentioned above, these stereotypes are socially circulated, and affect interactions between speakers of a language community. Given that the media, as an institution of power, play a decisive role in reproducing and reinforcing these stereotypes (cf. Moody 2013; Stuart-Smith 2006; Van den Bulck 2001), we used TV mass culture texts ${ }^{7}$ as stimulus for triggering the pupils' attitudes.

We used, therefore, excerpts from a popular television commercial by a major mobile phone company (Vodafone), which had been broadcasted in Greek television in 2011-2012. The commercial takes place in a fictional village, obviously rural, and depicts the romance between Kitsos and Tassoula, two young speakers of a regional Greek variety. Its aim is to promote mobile telephone services. The variety used by the characters of the commercial includes features coming from several northern Greek dialects. Among other things, it includes northern vocalism where unstressed mid vowels [e] and [o] are raised to $[\mathrm{i}]$ and $[\mathrm{u}]$ respectively, and unstressed high vowels $[\mathrm{i}]$ and $[\mathrm{u}]$ are typically

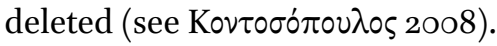

A second reason this particular commercial was chosen was the geographical origin of the variety used, which - as mentioned in 4.2-ensures a degree of geographical and psychological distance from our Southern Greek informants.

The third advantage is that neither the visual input of the ad, nor its comedic content invoke stereotypical images of rural peasants; consequently, they cannot influence the pupils' perception of the geographical variety in this direction. In particular, the characters of the ad are not represented as stereotypical peasants, as they are inhabitants of a rural village, using a dialectal variety (elements that construe a traditional image of peasantry), while, at the same time, Tassoula is a 'fashion victim', and Kitsos is a 'technology freak' (innova-

7 Mass culture texts are texts that are addressed to the general public. Examples include television series, commercials, films and songs (see $\Sigma \tau \dot{\alpha} \mu 0 v 2012$ ). 
tive characteristics in the rural setting). ${ }^{8}$ The commercial systematically uses a combination of stereotypical and non-stereotypical elements, a combination that cancels any visual triggering of stereotypical notions of ruralness and peasantry.

\subsection{Quantitative tools}

For the analysis of the data collected with the questionnaire, we employed various statistical tests, both non-parametric (such as One-Sample Chi-Square Test, Related-Samples Friedman's Two-Way Analysis of Variance by Ranks) and parametric (such as T-test, Anova Test, and Correlation Test), depending on the characteristics of the independent and dependent variables. More specifically, parametric tests were used when the dependent variable was scalar, and non-parametric tests were used when the dependent variables were nominal or ordinal.

Furthermore, Factor Analysis was run on pupils' assessments. The statistical analysis reduces the variability between a large number of possibly related parameters, into a smaller number of unrelated and underlying factor groups. The result of Factor Analysis was the classification of the seventeen characteristics into four factor groups on the basis of pupils' assessments.

\section{$5 \quad$ Findings}

\subsection{Beliefs about the acceptability of geographical varieties}

As regards the pupils' beliefs about the acceptability of geographical varieties, Figure 1 shows that most children of our sample expect the regional variety under study to be used in more rural areas. Specifically, it seems that pupils do not expect the use of the dialect in large urban centres, such as the cities of Athens or Patras, as only a small percentage $(8 \%)$ chooses these areas as locations where it is likely to hear a geographical variety similar to the one used in the commercial. This percentage is higher for provincial cities such as Pyrgos $(24 \%)$ and towns such as Kato Achaia $(34 \%)$. Lastly, a significantly high percentage of the pupils of our sample $(81 \%)$ expects the use of a geographical variety in a village. The Related-Samples Friedman's Two-Way Analysis

8 These are the terms used by the younger speakers (i.e., in English). By 'fashion victim', we mean a "slave to fashion", someone who always wears very fashionable clothes which sometimes might not suit him/her, and by 'technology freak' we mean someone who is a computer expert. 
It is possible to hear people speak like Kitsos and Tassoula in:

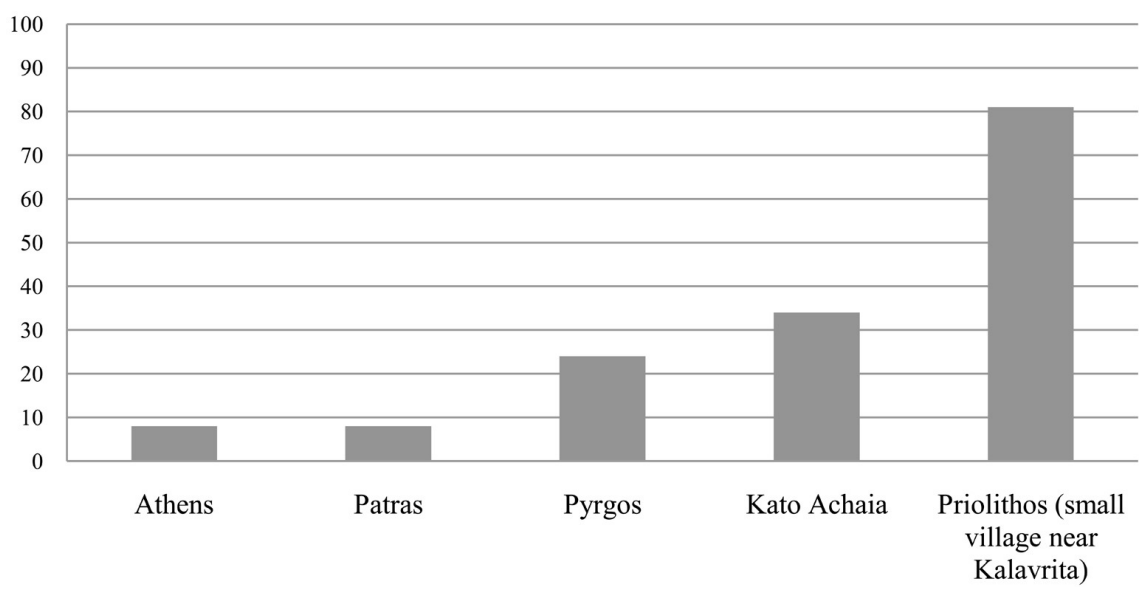

FIGURE 1 Histogram of the geographical areas where the use of a dialect is expected

of Variance by Ranks showed the above findings to be statistically significant (Sig.= 0.000). ${ }^{9}$

As regards the communicative circumstances appropriate for the use of a geographical variety, Figure 2 shows that pupils do not expect the use of a dialect in the town hall or at school (percentage of $4 \%$ and $5 \%$, respectively). In other words, pupils associate the environment of the town hall and the school with formal communicative circumstances, in which they consider dialect use to be out of place. On the other hand, they consider it more likely to encounter dialectal speech in more informal communicative environments, such as at home $(41 \%)$, in their neighborhood $(42 \%)$, and in the village square $(51 \%)$. Statistical analysis showed that children view the traditional coffee shop as the most likely communicative environment for the use of a geographical variety $(75 \%)$. The latter finding is not surprising, as the traditional coffee shops in Greece are the loci where elderly men socialize daily with their peers. This particular group of people often embody tradition and their speech includes various dialectal elements (Koupớn 1997, 2007).

The children may possibly consider the use of a dialect less likely in social environments such as the school and the town hall because they have associated these bodies of institutional power with the pursuit of linguistic homogeneity, the promotion of the standard language and, therefore, the use of SMG

9 The sum of the percentages depicted in Figure 1 is more than one hundred due to the students being able to make more than one choice in their responses. 
It is possible to hear people speak like Kitsos and Tassoula:

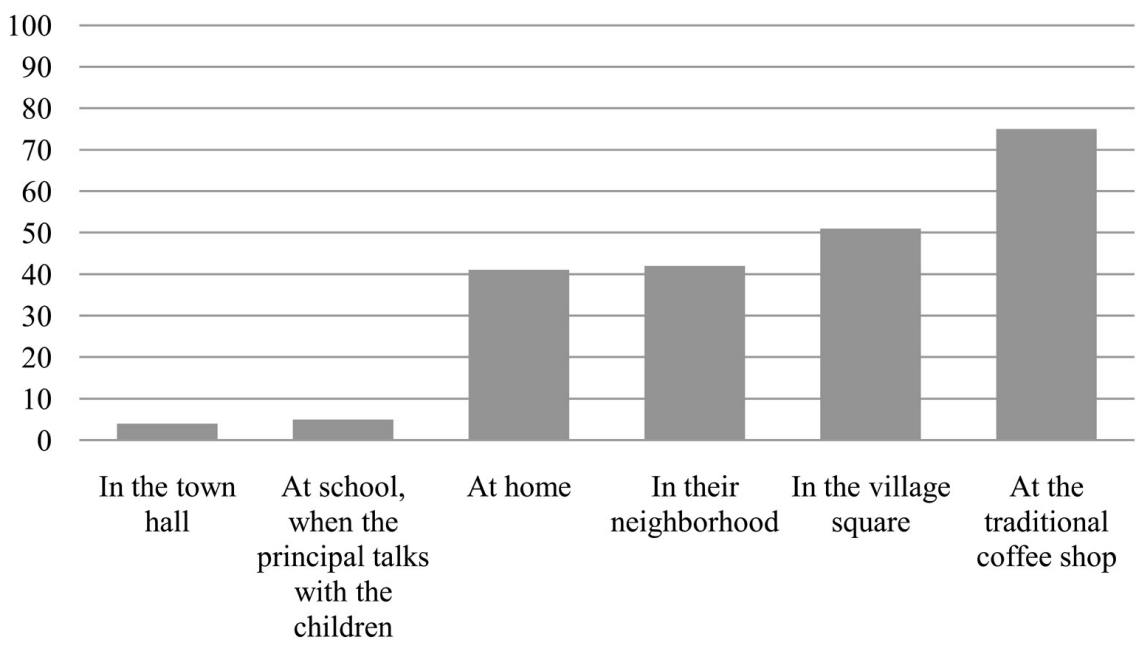

FIGURE 2 Histogram showing the communicative circumstances of geographical variety use

(see Fairclough 1989). Conversely, the children seem to perceive the village and the traditional coffee shop as environments that do not stigmatize the use of dialect, probably because they are not institutional bodies that promote linguistic homogenization. The Related-Samples Friedman's Two-Way Analysis of Variance by Ranks showed the above findings to be statistically significant (Sig.= 0.000). ${ }^{10}$

In order to delve into the use of dialect in formal communicative circumstances, we asked the children if they would expect to hear dialectal speech similar to the speech of the TV characters in the commercial from a teacher in the classroom, a journalist on television, or a doctor at his/her office. Figure 3 shows the children's overwhelmingly negative response regarding all three communicative circumstances.

To all three questions, the pupils replied 'Not at all' to a percentage above $65 \%(66.3 \%, 67.7 \%$ and $76.6 \%$ respectively), while the negative responses 'Not at all' and 'A little' together amounted for more than $89 \%$ (reaching $89.2 \%$ for the teacher, $95.8 \%$ for the journalist and $96.8 \%$ for the doctor). The OneSample Chi-Square Test showed the above results to be statistically significant, with a significance of o.0oo for all three questions.

10 The sum of the percentages depicted in Figure 2 is more than one hundred due to the students being able to make more than one choice in their responses. 
Is it possible to hear

a journalist on television speak like Kitsos and Tassoula?
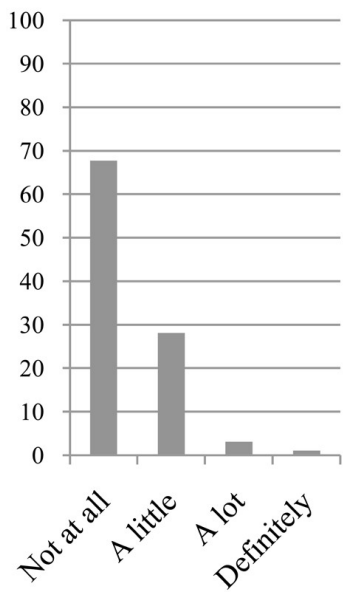

Is it possible to hear a new teacher speak

like Kitsos and

Tassoula, on the first day they enter your classroom to meet you for the first time?
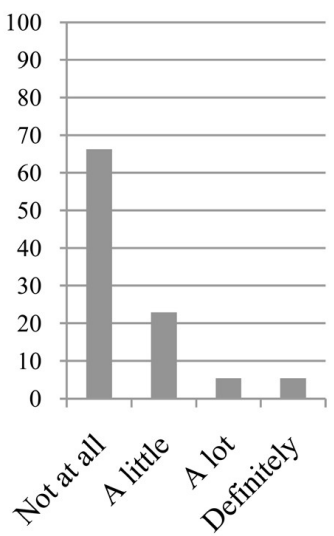

Is it possible to visit a doctor's office for the first time, along with your parents, and hear the doctor speak like Kitsos and Tassoula?

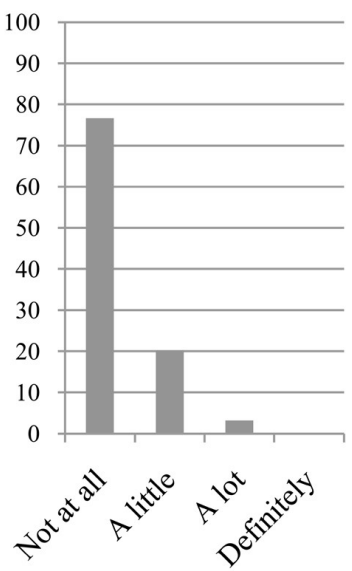

FIGURE 3 Histograms showing the use of geographical variety in formal communicative circumstances

According to the children's responses, the doctor's office is the least likely place for a geographical variety to be used. In fact, the children of our sample seem not to expect an authority figure, i.e. the doctor, to use a divergent and low prestige geographical variety when exerting authority. The journalist comes next, and the teacher comes last. This sequence may possibly relate to the fact that children have a more familiar and direct relationship with the teacher, and therefore consider it more likely to hear the teacher use a geographical variety in formal communicative circumstances. To the opposite effect, the doctor may be a more distanced figure, perhaps because of the children's fear of doctors, so in this case they consider it less likely to hear a geographical variety in a doctor's office.

To sum up, the findings of the statistical analysis show that children associate the use of a geographical variety with rural areas and informal communicative settings, and do not consider it likely to be used in formal communicative circumstances by individuals of high status. We can assume that the children of our sample view geographical varieties as elements associated with specific geographical and communicative frameworks, and used by specific social categories. These findings suggest that the pupils are in line with dominant metapragmatic stereotypes which promote language varieties as strictly 
bounded systems. In other words, they do not seem to challenge the dominant view of language varieties as distinct and autonomous systems.

\subsection{Beliefs about geographical varieties and dialect speakers: overt and covert prestige}

As seen in Section 4.3 above, the children were asked to evaluate the geographical variety used in the television commercial, using a four-point scale to assess the seventeen different characteristics provided. The answers of the pupils were used as input to Factor Analysis, which grouped the seventeen characteristics into four different categories. Each category relates to different aspects of the overt and covert prestige of the geographical variety.

Table 1 shows how the 17 characteristics were grouped by Factor Analysis into four categories.

Interestingly, numerous studies on language attitudes, have systematically grouped the participants' assessments into three categories: a) competence, b) social prestige/attractiveness, and c) personal integrity/reliability (see Preston 2003; Ryan and Giles 1982). In fact, the characteristics grouped together under the competence category related to the standard language variety, while the characteristics grouped under the social prestige and personal integrity categories are mostly associated with the use of geographical varieties (Preston 2003; Ryan and Giles 1982.). In the present research, the Factor Analysis grouped the 17 characteristics according to the children's evaluative assessments into four categories, three of which were very similar to the above categories.

The first category presents similarities to the characteristics grouped into the competence category and relates to the standard language variety (Preston 2003; Ryan and Giles 1982). In the present study, this category, as it emerges from the children's answers, includes characteristics that denote the lack of overt prestige of geographical varieties, that is the lack of acceptability in wider society. This category includes terms such as indifferent, insignificant, incongruous, useless, and outdated, attributing negative characteristics to the geographical variety and consequently to its speakers. It should be noted that these language attitudes have already developed during childhood (see also Kounnapi 2006; Pavlou 1999; Rosenthal 1974; van Bezooijen 2002; in Section 3).

The pupils' answers also give rise to two different categories, which systematically emerge in previous studies on language attitudes (see Preston 2003; Ryan and Giles 1982) and relate to dialect speakers' social attractiveness (second category) and personal reliability (fourth category). Specifically, the second category includes assessments such as intelligent, important, and beautiful, denoting that the pupils evaluate positively the social attractiveness of speakers who 
TABLE 1 Evaluative assessments of geographical variety and dialect speakers

\begin{tabular}{|c|c|c|c|c|}
\hline $\begin{array}{l}\text { Evaluative } \\
\text { assessment }\end{array}$ & $\begin{array}{l}\text { 1st category: } \\
\text { overt prestige }\end{array}$ & $\begin{array}{c}\text { 2nd category: } \\
\text { personal integrity } \\
\text { (within a } \\
\text { community) }\end{array}$ & $\begin{array}{l}\text { 3rd category: } \\
\text { humorous } \\
\text { stigmatization }\end{array}$ & $\begin{array}{l}\text { 4th category: } \\
\text { speakers' social } \\
\text { prestige (within } \\
\text { a community) }\end{array}$ \\
\hline Indifferent & .825 & -.025 & -.047 & -.139 \\
\hline Insignificant & .788 & -.007 & .134 & -.134 \\
\hline Incongruous & .743 & -.115 & -.040 & .035 \\
\hline Unappealing & .733 & -.179 & .319 & .050 \\
\hline Useless & .698 & -.242 & .176 & -.052 \\
\hline Outdated & .590 & .001 & .209 & .223 \\
\hline Intelligent & -.226 & .802 & .135 & .001 \\
\hline Important & -.098 & .783 & -.196 & .224 \\
\hline Beautiful & -.033 & .646 & -.069 & .179 \\
\hline Funny & .026 & -.002 & .800 & .213 \\
\hline Weird & .190 & .091 & .697 & -.092 \\
\hline Stupid & .293 & -.186 & .545 & -.130 \\
\hline Incorrect & .341 & -.395 & .488 & -.008 \\
\hline Friendly & -.201 & .287 & -.092 & .765 \\
\hline Rustic & .202 & -.176 & .082 & .702 \\
\hline Cheerful & -.013 & .298 & .060 & .687 \\
\hline Nice & -.046 & .377 & .135 & .457 \\
\hline
\end{tabular}

use a geographical variety. It is interesting that pupils evaluated the geographical variety positively in connection with the three characteristics mentioned above, despite the fact that neither of the commercial characters is portrayed as beautiful or bright.

The fourth category includes various judgements (including friendly, nice, and cheerful) revealing the children's assessment of the speakers' personal reliability. It should be noted that Factor Analysis included the term rustic in this fourth category. The specific evaluative judgement could have both negative (e.g. rube, unlettered) and positive (e.g. traditional bread, namely, healthy, tasty, fresh, genuine) connotations. Associating this characteristic with the others of the fourth category (friendly, cheerful, nice), it is clear that this term takes 
positive connotations. So, the combined interpretation of the characteristics of the fourth category reveals that the students possibly associate the use of geographical varieties with characteristics of proximity and solidarity, i.e. notions connected with covert prestige and the strong social bonds often found in rural environments (Trudgill 1974, 1975).

It is worth mentioning that Factor Analysis did not group together the characteristics cheerful and funny, which indicated that the two characteristics carry different connotations for the children in connection with the geographical diversity.

Although the first category of negative evaluative assessments seems to logically contradict the pupils' positive assessments in the second and fourth categories, it should be noted that this specific distinction appears regularly in several studies on language attitudes (see Preston 2003; Ryan and Giles 1982), reflecting the distinction between overt and covert prestige, depending on whether informants assess a geographical variety or its speakers in the context of a specific dialect-speaking social group or according to the values that are acceptable in the wider society.

In the present research, apart from the three assessment categories that appear regularly in numerous studies on language attitudes, Factor Analysis identified a further category (see Table 1, third category), including assessments such as funny, weird, stupid, and incorrect. We argue that these assessments reflect the children's beliefs about the humorous stigmatization of the geographical varieties and dialect speakers. Specifically, the classification of funny and weird under a common category reveals that children associate deviation with humor, contrasting it to what is socially expected and acceptable (see Attardo 1994). Pupils seem to perceive the representation of nonstandard varieties in our stimulus as incompatible with the mass media setting, and therefore funny. This category also includes the assessments stupid and incorrect, two characteristics with highly negative connotations. The grouping together of these four characteristics suggests that pupils perceive the representation of the geographical variety, as well as its speakers, as humorously stigmatized by

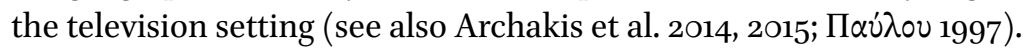

To sum up the conclusions on the results of Factor Analysis, it seems that a dominant belief of the pupils is that geographical varieties entail no overt prestige and are negatively evaluated by wider society (based on the six negative characteristics that form the first group of Factor Analysis). The children's negative language attitudes to geographical varieties and their belief that these varieties lack overt prestige demonstrates that pupils are influenced by the metapragmatic stereotypes of linguistic homogeneity, through which the dominance of the standard language is promoted and the use of language varieties 
is devalued. In fact, according to their assessments, pupils seem to believe that geographical varieties are targeted and humorously stigmatized in their television representation (according to the characteristics that construct the third group of the Factor Analysis). Their answers show that children in the last grades of elementary school are already influenced by metapragmatic stereotypes reproduced by Greek media, aiming to promote the standard language variety and stigmatize geographical varieties (Archakis et al. 2014).

Apart from the absence of overt prestige, the results of Factor Analysis Test on our attitudinal test reveal that children evaluate geographical variety and dialect speakers positively, both as individuals (in terms of the characteristics of the second group of Factor Analysis) and as social actors (in terms of the characteristics of the fourth group), with terms that reveal aspects of covert prestige such as proximity and solidarity.

\subsection{The pupils' social characteristics and their beliefs about dialect speakers' overt and covert prestige}

We now investigate any statistically significant correlations between the four categories that emerged from the Factor Analysis and social factors such as the pupils' gender, the social stratification of the school area and the pupils' performance in language subjects.

As the results of Factor Analysis showed, a dominant belief among pupils is that geographical varieties lack overt prestige. This belief shows no statistically significant differentiation regarding the pupils' gender, ${ }^{11}$ the social stratification of the area where their school is located, ${ }^{12}$ or their performance in language subjects. ${ }^{13}$ This finding demonstrates that the devaluation of geographical varieties and dialect speakers in wider society is also widely held by the pupils of the sample, probably because of the social stigmatization by institutions of power, such as education and the media (see Section 3).

As regards pupils' language attitudes towards the second category of Factor Analysis (i.e. the one described as social attractiveness), the statistical analysis demonstrated a statistically significant correlation with the social status of the area where the school is located. Specifically, the Pearson Correlation showed that in schools located in areas of lower social status, the pupils' assessments of the dialect speakers' personality are more positive. ${ }^{14}$

\footnotetext{
11 Chi-Square Test Sig. $(2$-tailed $)=0.581$, Boys: Mean $=-0.021$, St. Dev. $=1.03$, Girls: Mean $=$ o.o89, St. Dev = o.88.

12 Pearson Correlation $=0.047$, Sig. $(2$-tailed $)=0.648$.

13 Pearson Correlation $=0.072$, Sig. $(2$-tailed $)=0.483$.

14 Pearson Correlation:-0.225, Sig. (2-tailed): 0.027, N: 96.
} 
It can be assumed that pupils from lower social status areas, located in villages populated mostly by farmers and manual workers, positively assess characteristics that refer to the social attractiveness of the geographical variety and the dialectal speakers because they are members of a rural or dialectal community themselves. This confirms previous studies, according to which speakers shape different attitudes towards geographical varieties, depending on whether they are also members of the dialect community (in-group) or not (out-group; see Preston 2003; Ryan and Giles 1982). The social parameters of the pupils' gender ${ }^{15}$ and performance in language subjects ${ }^{16}$ do not seem to correlate quantitatively with how they perceive the social attractiveness of the geographical variety and its speakers.

As to the possible correlations between the fourth category of Factor Analysis (i.e. personal reliability) and the social parameters of gender, ${ }^{17}$ the social stratification of the school area ${ }^{18}$ and the pupils' performance in language subjects, the quantitative analysis showed no statistically significant correlation other than a tendency of pupils with a higher performance in language subjects to attribute more positive assessments to dialect speakers, in terms of proximity, friendliness, and solidarity. ${ }^{19}$

It can be assumed that pupils with a higher performance in language subjects have the linguistic sensitivity to perceive the connotations of language elements, depending on the communicative context in which they are used. Consequently, these pupils display a stronger belief that the use of a geographical variety in a rural communicative context entails covert prestige and denotes proximity and solidarity.

Lastly, regarding the humorous stigmatization of dialect speakers and geographical varieties, the quantitative analysis showed no statistically significant correlations with the social variables of gender ${ }^{20}$ and the social status of the school location, ${ }^{21}$ except a tendency to relate the pupils' high performance in

\footnotetext{
15 Chi-Square Test Sig. $(2$-tailed $)=0.701$, Boys: Mean $=0.037$, St. Dev. $=1.01$, Girls: Mean $=-$ 0.042, St. Dev. = 1.00.

16 Pearson Correlation $=-0.053$, Sig. $(2$-tailed $)=0.608$.

17 Chi-Square Test Sig. $(2$-tailed $)=0.617$, Boys: Mean $=0.006$, St. Dev. $=1.05$, Girls: Mean $=$ o.ogo, St. Dev = 0.77.

18 Pearson Correlation $=0.109$, Sig. $(2$-tailed $)=0.292$.

19 Pearson Correlation: 0.187 , Sig. (2-tailed): o.o68, N: 96.

20 Chi-Square Test Sig. (2-tailed) $=0.762$, Boys: Mean $=-0.051$, St. Dev. $=1.02$, Girls: Mean $=$ o.010, St. Dev. $=0.92$.

$21 \quad$ Pearson Correlation $=0.090$, Sig. $(2$-tailed $)=0.381$.
} 
language subjects with their ability to recognize how the geographical variety and its speakers is represented in a humorous and at the same time demeaning way. ${ }^{22}$

This could be attributed to the fact that pupils with a higher performance are more accomplished in the standard language, and have therefore developed a greater awareness of the dominant linguistic ideologies promoted by media discourse. It is therefore easier for them to perceive that TV characters (such as the ones used in this study) who do not follow dominant language standards are humorously targeted in their representation in TV (see Archakis

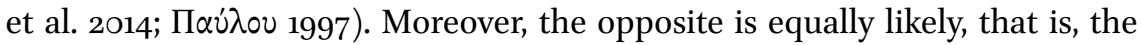
ability of certain pupils to display greater ease in perceiving different assessments and differences between varieties may help them have a higher school performance (e.g. by preferably using the standard language at school).

To sum up, we observe that the attitudes of the children as regards the lack of overt prestige are not affected by social parameters such as gender, social stratification, and pupils' performance in language subjects. This homogeneity could be interpreted as a result of the dominant metapragmatic stereotype of linguistic homogeneity in Greece (see Section 3).

As to the pupils' beliefs about the social attractiveness of the geographical varieties and their speakers, the statistical analysis showed a statistically significant negative correlation with the social status of the area where the pupils' school is located-i.e. the lower the social status of the area of the school, the more positive the assessments from the pupils. As mentioned above, this significant differentiation could indicate that members of different communities could shape different metapragmatic stereotypes, at least in connection with the social attractiveness of the geographical variety and its speakers, depending on whether they assess the geographical variety and its speakers as in-group members of a dialect speaking community or, assessing it from a distance, as out-group members.

Further quantitative analysis showed a tendency of interrelation between performance in language subjects and the other two categories of Factor Analysis, i.e. the attitudes of proximity, friendliness and solidarity, as well as the humorous stigmatization of the geographical variety and its speakers. These findings could indicate that the pupils have acquired the sociolinguistic competence to perceive the metapragmatic stereotypes shaped by powerful institutions (like education and mass media), as well as the communicative circumstances in which not only are dialect speakers not stigmatized, but actually

Pearson Correlation: 0.173, Sig. (2-tailed): o.o92, N: 96. 
enjoy positive social prestige, and this competence has helped them to enhance their performance at school.

Over the past decades, contemporary sociolinguistics has challenged the existence of fixed and rigid linguistic boundaries, thus focusing on how the speakers themselves define language varieties and how specific linguistic choices end up being perceived as language varieties. In other words, the focus is not on the geographical and/or social boundaries of a variety, but on the speakers' beliefs regarding the geographical and/or social context of specific language elements, which are perceived as varieties. Emphasis is therefore placed on the speakers' language attitudes, which stem from metapragmatic stereotypes, i.e. the speakers' internalized models for evaluating the use of specific language elements.

In this context, we studied how elementary school pupils perceive and define nonstandard geographical varieties. Our aim was to investigate whether they delimit a language variety in terms of the acceptability of its use, and which metapragmatic stereotypes contribute to this process. Moreover, we aimed at revealing the children's beliefs about the overt and covert prestige of geographical varieties and dialect speakers, as well as whether these beliefs are affected by social parameters such as gender, the social stratification of the school location, and the pupils' performance in language subjects.

According to our findings, pupils do not seem to challenge the assumption of distinct and autonomous varieties. Essentially, the children of our sample perceive language varieties as elements that correspond to specific geographical and communicative contexts, and to specific social categories. More specifically, the results of our research can be summarized as follows: first, pupils associate the use of dialect speech with rural areas and informal communicative environments. At the same time, children consider the use of geographical varieties in formal communicative circumstances as highly inappropriate.

In addition, pupils attribute covert prestige to the geographical variety, positively assessing dialect speakers within their community, both in terms of social attractiveness and personal reliability. Nevertheless, when pupils consider geographical varieties isolated from their 'natural' environment, they assess them negatively and fail to attribute overt prestige. Moreover, pupils do not expect an educated person of high status (such as a doctor, journalist, or teacher) to use a geographical variety in formal professional communicative circumstances. Finally, children recognize the humorous stigmatization of the geographical variety by the media. 
The language attitudes of the pupils in our sample confirm previous findings of both international literature (see Diercks 2002; Preston 1999, 2003) and research in Greece (see Koupóńs 1997, 2001, 2002, 2007; Pappas 2006; П $\alpha \pi \pi \alpha ́ s$

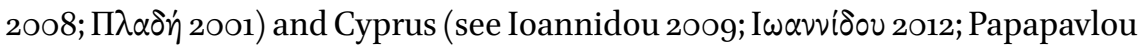

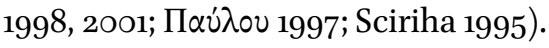

Moreover, by confirming previous research findings (see Kounnapi 2006; Pavlou 1999; Rosenthal 1974), our research showed that some of the pupils' language attitudes are statistically related to social parameters such as the social status of the school location and the pupils' performance in language subjects. Specifically, positive assessments of the geographical variety and its speakers' social attractiveness are more dominant in children with a lower social background. This could be due to the in-group membership of the low social background pupils, as opposed to pupils from higher social backgrounds, who assess the geographical variety and its speakers from a distance (out-group). Furthermore, pupils with a higher performance in language subjects tend to easily perceive the metapragmatic stereotypes shaped by television texts, as well as the communicative circumstances in which dialect speakers are not stigmatized but can actually enjoy positive social prestige.

The pupils' responses to the study we conducted on their attitudes show that children in the last grades of elementary school are already influenced by metapragmatic stereotypes and ideologies reproduced by Greek media, which aim to promote the standard language variety and stigmatize geographical vari-

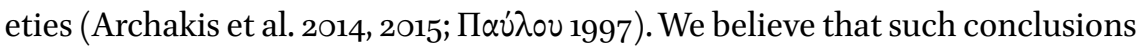
help promote the need for the development of critical literacy by pupils, so that they can be able to detect, instead of accepting uncritically, the metapragmatic stereotypes that are propagated by mass culture texts and that influence their language attitudes.

\section{References}

Agha, Asif. 1998. Stereotypes and Registers in Honorific language. Language in Society 27.151-193.

Agha, Asif. 2004. Registers of Language. A Companion to Linguistic Anthropology, ed. by Alessandro Duranti, 23-45. Oxford and New York: Blackwell.

Agha, Asif. 2007. Language and Social Relations. Cambridge: Cambridge University Press.

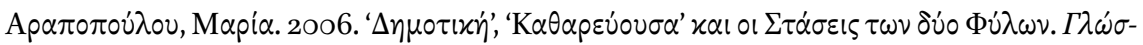

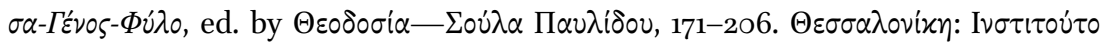

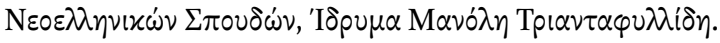


Archakis, Argiris, Sofia Lampropoulou, Villy Tsakona and Vasia Tsami. 2014. Linguistic Varieties in Style: Humorous representation in Greek mass culture texts. Discourse, Context and Media 3.46-55.

Archakis, Argiris, Sofia Lampropoulou, Villy Tsakona and Vasia Tsami. 2015. Style and Humour in Greek Mass Culture Texts. Culture's Software: Communication Styles, ed. by Dorota Brzozowska and Władysław Chłopicki, 16-38. Cambridge: Cambridge Scholars Publishing.

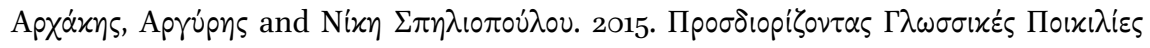

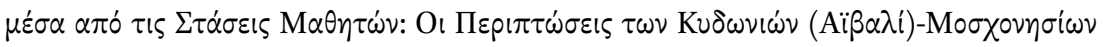

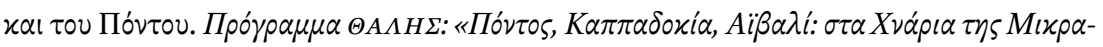

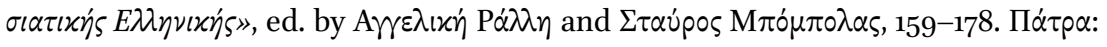

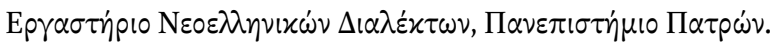

Attardo, Salvatore. 1994. Linguistic Theories of Humor. Berlin and New York: Mouton de Gruyter.

Baker, Colin. 1992. Attitudes and Language. Clevedon, Bristol and Adelaide: Multilingual Matters.

Blommaert, Jan. 2006. Language Ideology. Encyclopedia of Language and Linguistics, ed. by Keith Brown, 510-522. Oxford: Elsevier.

Blommaert, Jan and Ben Rampton. 2011. Language and Superdiversity. Diversities 13.120.

Busch, Brigitta. 2012. The Linguistic Repertoire Revisited. Applied Linguistics 33.503523 .

Cremona, Cristiana and Elizabeth Bates. 1977. The Development of Attitudes toward Dialect in Italian Children. Journal of Psycholinguistic Research 6.223-232.

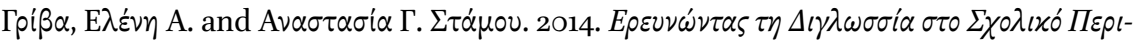

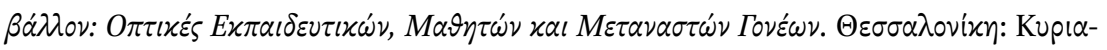
xí̀n.

Dailey-O'Cain, Jennifer. 1999. The Perception of Post-unification German Regional Speech. Handbook of Perceptual Dialectology, Vol. 1, ed. by Dennis R. Preston, 227242. Amsterdam and Philadelphia: John Benjamins.

Day, Richard. 1980. The Development of Language Attitudes and Preferences. TESOL Quarterly 14.27-37.

Diercks, Willy. 2002. Mental Maps: Linguistic-geographic Concepts. Handbook of Perceptual Dialectology, Vol. 2, ed. by Daniel Long and Dennis R. Preston, 51-70. Amsterdam and Philadelphia: John Benjamins.

Eckert, Penelope. 2012. Three Waves of Variation Study: The Emergence of Meaning in the Study of Sociolinguistic Variation. Annual Review of Anthropology 41.87100.

Fairclough, Norman. 1989. Language and Power. London and New York: Longman.

Fasold, Ralph. 1984. The Sociolinguistics of Society. Oxford and New York: Blackwell. 
Giles, Howard and Peter F. Powesland. 1975. Speech Style and Social Evaluation. London and New York: Academic Press.

Grootaers, Willem, A. 1999. The Discussion Surrounding the Subjective Boundaries of Dialects. Handbook of Perceptual Dialectology, Vol. 1, ed. by Dennis R. Preston, $115^{-}$ 129. Amsterdam and Philadelphia: John Benjamins.

Guy, R. Gregory. 2013. The Cognitive Coherence of Sociolects: How do Speakers Handle Multiple Sociolinguistic Variables? Journal of Pragmatics $5^{2.63}-71$.

Heller, Monica. 2007. Bilingualism as Ideology and Practice. Bilingualism: A Social Approach, ed. by Monica Heller, 1-21. Basingstoke, Hampshire and New York: Palgrave Macmillan.

Hinskens, Frans and Gregory R. Guy. 2016. Introduction. Linguistic Coherence: Systems, Repertoires and Speech Communities. Coherence, Covariation and Bricolage. Various Approaches to the Systematicity of Language Variation, ed. by Frans Hinskens and Gregory R. Guy. Lingua 172-173.1-9.

Hudson, Richard A. 1996. Sociolinguistics, 2nd edition [1st edition: 1980]. Cambridge: Cambridge University Press.

Inoue, Fumio. 1999. Classification of Dialects by Image: English and Japanese. Handbook of Perceptual Dialectology, Vol. 1, ed. by Dennis R. Preston, 147-16o. Amsterdam and Philadelphia: John Benjamins.

Ioannidou, Elena. 20o9. Using the 'Improper' Language in the Classroom: The Conflict between Language Use and Legitimate Varieties in Education. Evidence from a Greek Cypriot Classroom. Language and Education 23.263-278.

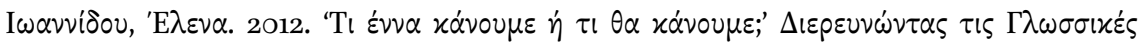

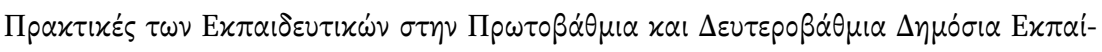
$\delta \varepsilon v \sigma \eta \sigma \tau \eta \nu$ Kú $\pi$ po. Selected Papers of the 1oth International Conference of Greek Linguistics (ICG L1O), ed. by Zoe Gavriilidou, Angeliki Efthymiou, Evangelia Thomadaki and Penelope Kambakis-Vougiouklis, $815-826$. Komotini: Democritus University of Thrace.

Johnstone, Barbara. 20o9. Pittsburghese Shirts: Commodification and the Enregisterment of an Urban Dialect. American Speech 84.157-175.

Johnstone, Barbara. 2011a. Dialect Enregisterment in Performance. Journal of Sociolinguistics $15.657-679$.

Johnstone, Barbara. 2011b. Making Pittsburghese: Communication Technology, Expertise, and the Discursive Construction of Regional Dialect. Language and Communication 31.3-15.

Johnstone, Barbara, Jennifer Andrus and Andrew E. Danielson. 2006. Mobility, Indexicality, and the Enregisterment of 'Pittsburghese'. Journal of English Linguistics 34.77104.

Jørgensen, Normann, J. and Kasper Juffermans. 2011. Superdiversity. Accessed June 10, 2013. http://www.academia.edu/1808420/Superdiversity.html. 


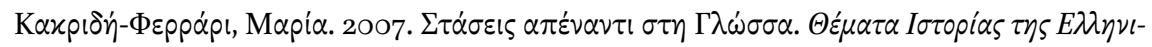

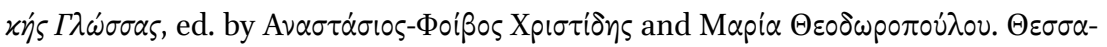

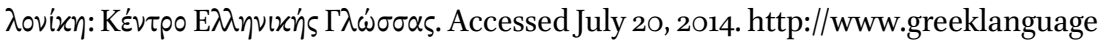
.gr/greekLang/studies/history/thema_o3/index.html.

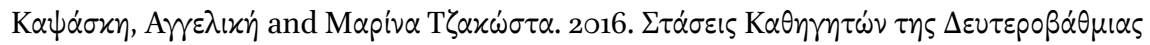

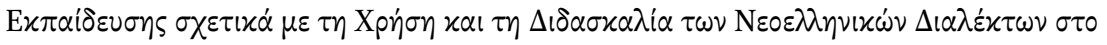

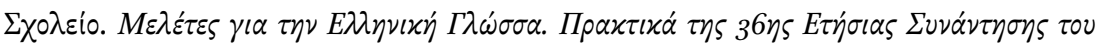

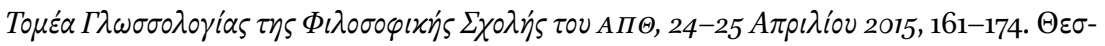

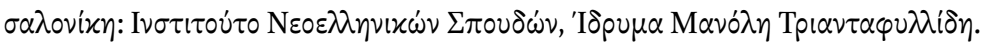

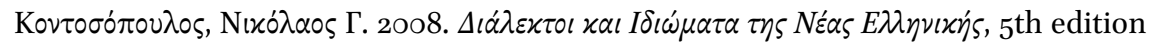

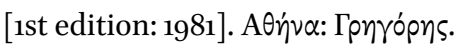

Kounnapi, Evgenia. 2006. Greek Cypriot Children's Language Attitudes in a Bidialectal

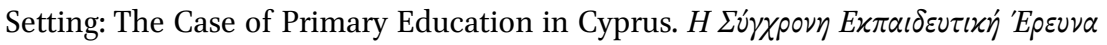

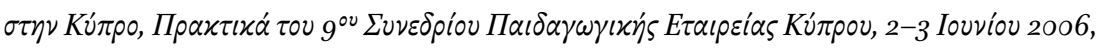

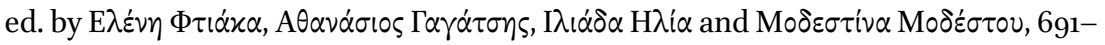

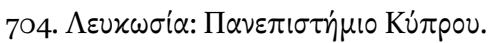

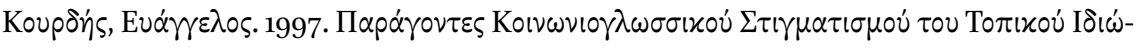

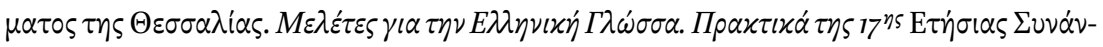

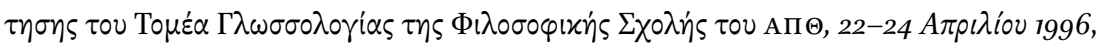

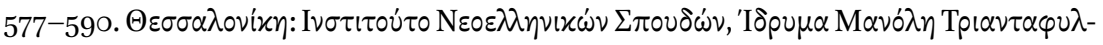
$\lambda i \delta \eta$.

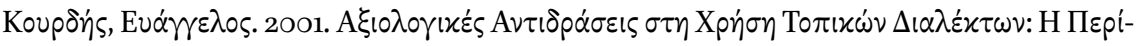

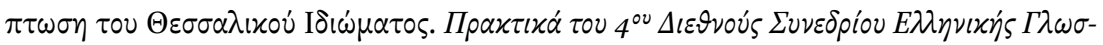

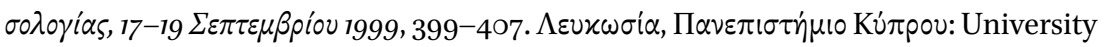
Studio Press.

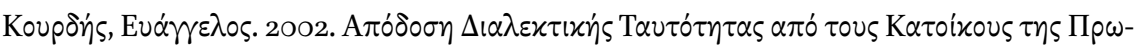

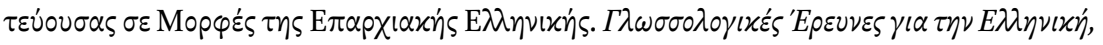

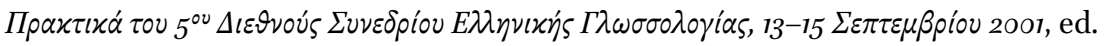
by Christos Clairis, 321-324. Sorbonne, Paris: L'Harmattan.

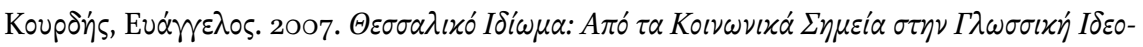

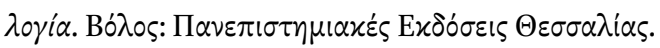

Lambert, Wallace E., Richard C. Hodgson, Robert C. Gardner and Samuel Fillenbaum. 196o. Evaluational Reactions to Spoken Language. Journal of Abnormal and Social Psychology 60.44-51.

Makoni, Sinfree and Alastair Pennycook, eds. 2007. Disinventing and Reconstituting Languages. Clevedon: Multilingual Matters.

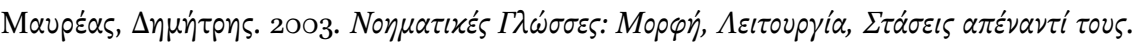

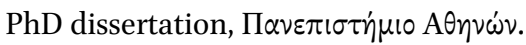

Moody, Andrew. 2013. Language ideology in the discourse of popular culture. The Encyclopedia of Applied Linguistics, ed. by Carol A. Chapelle. Oxford: Blackwell. 
Accessed June 10, 2013. http://onlinelibrary.wiley.com/store/10.1002/9781405198431/ asset/homepages/5_Language_Ideology_in_the_Discourse_of_Popular_Culture.pdf $? \mathrm{v}=1 \& \mathrm{~s}=8344 \mathrm{a} 7 \mathrm{bg1a2}$ oceea92aoed6feoaaa4eda66f7037.html.

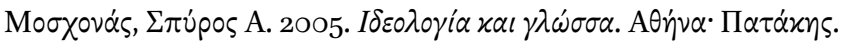

Otsuji, Emi and Alastair Pennycook. 2010. Metrolingualism: Fixity, Fluidity and Language in Flux. International Journal of Multilingualism 7.240-254.

Papapavlou, Andreas N. 1998. Attitudes toward the Greek Cypriot Dialect: Sociocultural Implications. International Journal of Sociology of Language 134.15-28.

Papapavlou, Andreas N. 2001. Mind your Speech:Language Attitudes in Cyprus. Journal of Multilingual and Multicultural Development 22.491-501.

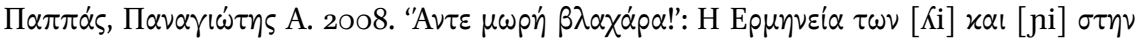

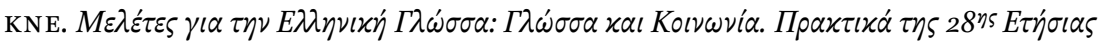

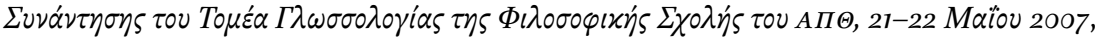

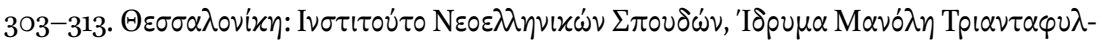
$\lambda i \delta \emptyset$.

Pappas, Panayiotis A. 2006. Stereotypes and /n/Variation in Patra, Greece: Results from a Pilot Study. Language Variation-European Perspectives: Selected Papers from the Third International Conference on Language Variation in Europe (ICLAVE3), ed. by Frans L. Hinskens, 153-167. Amsterdam: John Benjamins.

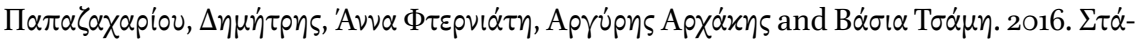

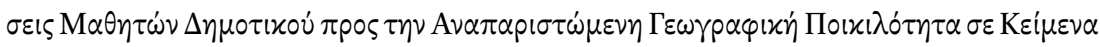

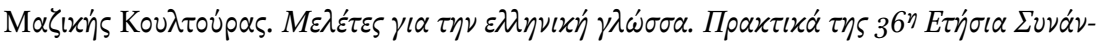

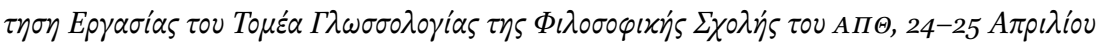

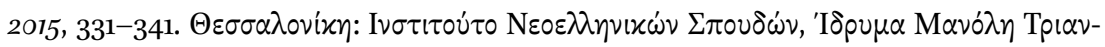
$\tau \alpha \varphi v \lambda \lambda i \delta \eta$.

Papazachariou, Dimitris, Anna Fterniati, Argiris Archakis and Vasia Tsami. 2017. Elementary School Pupils' Attitudes towards Geographical Variation in Popular Culture Texts: Evidence from Greek Data. MENON: Journal of Educational Research 4.76-86.

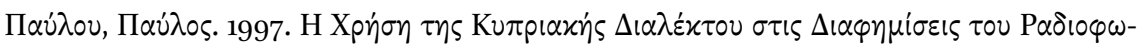

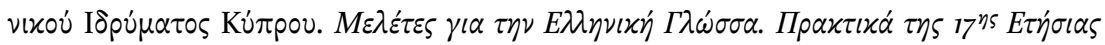

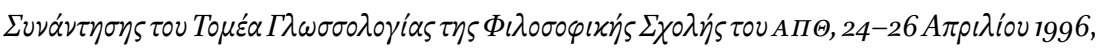

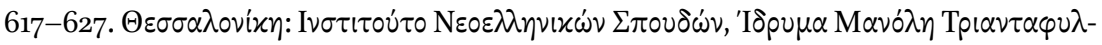
$\lambda i \delta$.

Pavlou, Pavlos. 1999. Children's Language Attitude in a Bidialectal Setting: Some Meth-

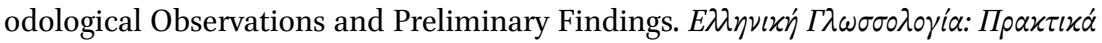

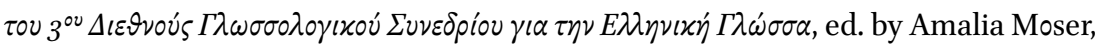

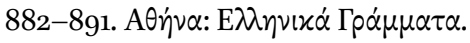

Pavlou, Pavlos and Andreas Papapavlou. 2004. Issues of Dialect Use in Education from the Greek Cypriot Perspective. International Journal of Applied Linguistics 14.243258 . 
Piller, Ingrid. 2001. Naturalization Language Testing and its Basis in Ideologies of National Identity and Citizenship. International Journal of Bilingualism 5.259-277.

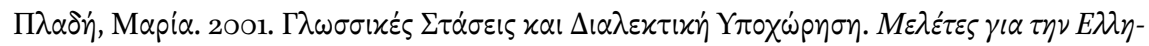

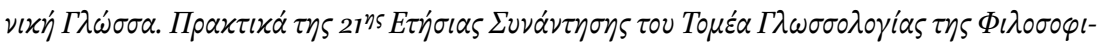

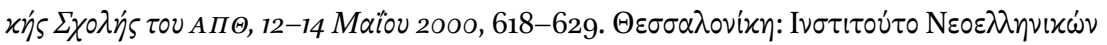

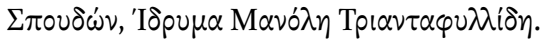

Preston, Dennis R. 1989. Perceptual Dialectology: Nonlinguists'Views of Areal Linguistics. Dordrecht and Providence: Foris.

Preston, Dennis R. 1999. A Language Attitude Approach to the Perception of Regional Variety. Handbook of Perceptual Dialectology, Vol. 1, ed. by Daniel Long and Dennis R. Preston, 359-373. Amsterdam and Philadelphia: John Benjamins.

Preston, Dennis R. 2003. Language with an Attitude. The Handbook of Language Variation and Change, ed. by J.K. Chambers, Peter Trudgill and Natalie Schilling-Estes. Oxford and New York: Blackwell. Accessed June 11, 2013.

http://www.blackwellreference.com/subscriber/tocnode?id=g9781405116923_ chunc_g978140051169235.html.

Rampton, Ben. 1995. Crossing: Language and Ethnicity among Adolescents. London and New York: Longman.

Rensink, Wim G. 1999. Informant Classification of Dialects. Handbook of Perceptual Dialectology, Vol. 1, ed. by Dennis R. Preston, 3-7. Amsterdam and Philadelphia:John Benjamins.

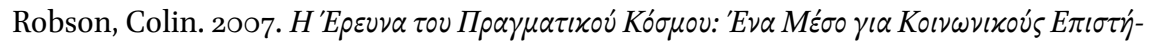

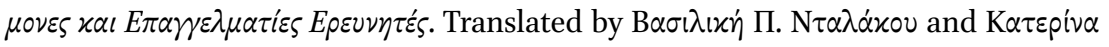
B $\alpha \sigma i \lambda$ เжоv'. Athens: Gutenberg.

Rosenthal, Marilyn S. 1974. The Magic Boxes: Pre-school Children's Attitudes towards Black and Standard English. The Florida FL Reporter $12.55^{-62}$, 92-93.

Ryan, Ellen Bouchard and Howard Giles, eds. 1982. Attitudes towards Language Variation: Social and Applied Context. London: Edward Arnold.

Sciriha, Lydia. 1995. The Interplay of Language and Identity in Cyprus. The Cyprus Review 7.7-34.

Silverstein, Michael. 1992. The Indeterminacy of Contextualization: When is Enough Enough? The Contextualization of Language, edited by Peter Auer and Aldo Di Luzio, 55-76. Amsterdam and Pennsylvania: John Benjamins.

Silverstein, Michael. 1993. Metapragmatic Discourse and Metapragmatic Function. Reflexive Language: Reported Speech and Metapragmatics, ed. by John A. Lucy, 3358. Cambridge: Cambridge University Press.

Silverstein, Michael. 2003. Indexical Order and the Dialectics of Sociolinguistic Life. Language and Communication 23.193-229.

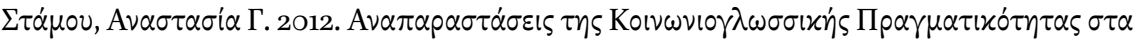

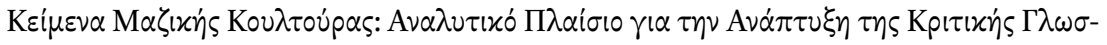

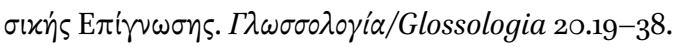


Stuart-Smith, Jane. 2006. The Influence of the Media. The Routledge Companion to Sociolinguistics, ed. by Carmen Llamas, Louise Mullany and Peter Stockwell, 140-148. London and New York: Routledge.

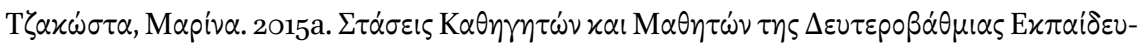

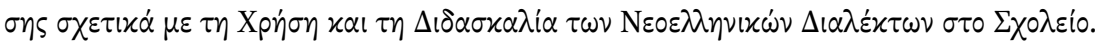
Paper presented at the 12th International Conference of Greek Linguistics (ICGL12). Berlin, Freie Universität, September 16-19.

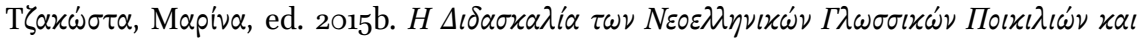

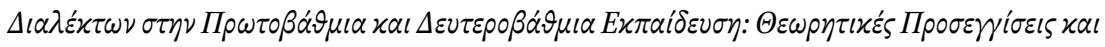

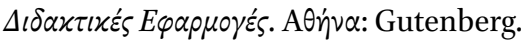

Trudgill, Peter. 1974. The Social Differentiation of English in Norwich. Cambridge: Cambridge University Press.

Trudgill, Peter. 1975. Sex, Covert Prestige and Linguistic Change in the Urban British English of Norwich. Language in Society 1.179-195.

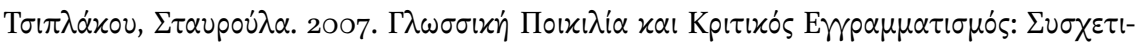

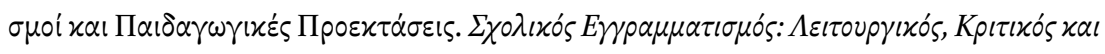

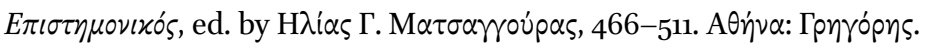

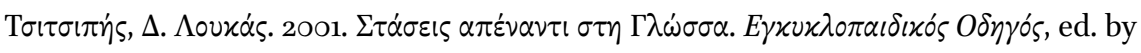

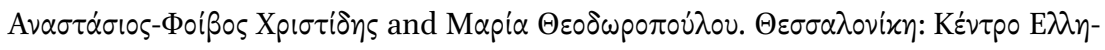

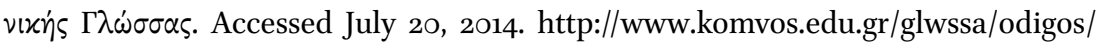
thema_b2/thema_pdf.

van Bezooijen, Renée. 2002. Aesthetic Evaluation of Dutch: Comparisons across Dialects, Accents, and Languages. Handbook of Perceptual Dialectology, Vol. 2, ed. by Daniel Long and Dennis R. Preston, 13-30. Amsterdam and Philadelphia: John Benjamins.

Van den Bulck, Hilde. 2001. Public Service Television and National Identity as a Project of Modernity: The Example of Flemish Television. Media, Culture and Society 23.5369.

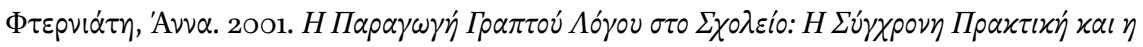

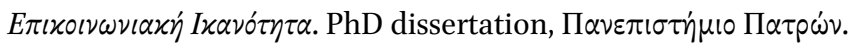




\section{Appendix}

Question for the findings presented in Table 1:

- What do you think about Kitsos' and Tassoula's way of speaking? Circle from 1 (=Not at all) to 4(=Definitely) the following descriptions.

\begin{tabular}{lcccc}
\hline & Not at all & A little & A lot & Definitely \\
\hline Weird & 1 & 2 & 3 & 4 \\
Funny & 1 & 2 & 3 & 4 \\
Incorrect & 1 & 2 & 3 & 4 \\
Nice & 1 & 2 & 3 & 4 \\
Beautiful & 1 & 2 & 3 & 4 \\
Stupid & 1 & 2 & 3 & 4 \\
Unappealing & 1 & 2 & 3 & 4 \\
Outdated & 1 & 2 & 3 & 4 \\
Cheerful & 1 & 2 & 3 & 4 \\
Useless & 1 & 2 & 3 & 4 \\
Indifferent & 1 & 2 & 3 & 4 \\
Incongruous & 1 & 2 & 3 & 4 \\
Friendly & 1 & 2 & 3 & 4 \\
Important & 1 & 2 & 3 & 4 \\
Intelligent & 1 & 2 & 3 & 4 \\
Rustic & 1 & 2 & 3 & 4 \\
Insignificant & 1 & 2 & & 4 \\
\hline
\end{tabular}

Question for the findings presented in Figure 1:

- It is possible to hear people speak like Kitsos and Tassoula in: 1. Athens, 2. Patras, 3. Pyrgos, 4. Kato Achaia, 5. Priolithos (small village near Kalavrita).

Question for the findings presented in Figure 2:

- It is possible to hear people speak like Kitsos and Tassoula: 1. in the town hall, 2. at school, when the principal of the school talks with the children, 3 . at home, 4 . in their neighborhood, 5 . in the village square, 6 . at the traditional coffee shop. 
Questions for the findings presented in Figure 3:

- Is it possible to hear a journalist on television speak like Kitsos and Tassoula? 1. Not at all, 2. A little, 3. A lot, 4. Definitely.

- Is it possible to hear a new teacher speak like Kitsos and Tassoula, on the first day they enter your classroom to meet you for the first time? 1. Not at all, 2. A little, 3. A lot, 4. Definitely.

- Is it possible to visit a doctor's office for the first time, along with your parents, and hear the doctor speak like Kitsos and Tassoula? 1. Not at all, 2. A little, 3. A lot, 4. Definitely. 